\title{
LANGUAGE, VALUES AND IDEOLOGY IN COMPLEX HUMAN SOCIETIES
}

\author{
J. Nescolarde-Selva, J.L. Usó-Doménech \\ Department of Applied Mathematics.University of Alicante. Alicante. Spain. \\ H. Gash \\ St Patrick's College, A College of Dublin City University, Dublin, Ireland
}

\begin{abstract}
Using language requires simultaneously verifying communication and the linguistic message of the speaker. There is, therefore, an emphasis on understanding, which is contained in the linguistic message. Understand goes beyond what is said, and includes the immediate connotations, that is, semantics in the strict sense. Language must, therefore, be interpreted, though it is indeed transferred by the immediate meanings of the linguistic code. In the present paper, the authors approached some of these issues from the point of view of the hermeneutics of spoken or written language, as a double proposal (ostensive and estimative) of the subject in relation to his reality
\end{abstract}

Keywords: Connotative significance, Denotative significance, Ethic, Estimative propositions, Expressiveness, Hermeneutics, Information, Prejudice, Values of judgment.

\section{INTRODUCTION}

Language, values and ideologies have been studied throughout the history of philosophy. However, as an Italian cyberneticist Silvio Ceccato (1961) pointed out, when adults looked at reality they didn't notice that the concept of reality had been established in childhood and so was assumed. Following this insight, certain attempts to model language focussed on the mental operations involved in making meaning (Glasersfeld, 1972). In the present paper a number of approaches to language values and ideology are reviewed with the aim of developing a mathematical basis for modelling these dimensions of meaning. Our intention is to develop a model that is consistent with radical constructivism following Ernst von Glasersfeld (1995), however we note that many of the sources reviewed here assumed relating ideas to reality was unproblematic but whose contribution to this domain remains significant.

From the 19 th century, discussions of the origin and the historical development of language by Herder and Humboldt were the "narrative" of the modern and postmodern disciplines of linguistics and the psychology of language, i.e., thinking about language. Aristotle's metaphysical argument on the importance of substance in understanding being is redividus in 20th century Logical Atomism. The essence of this theory is to practice logically perfect language (e.g. subject, predicate sentences, fact stating sentences, theory of types. Logic is the study of influence in reasoning as reasoning is carried on in language to analyze various kinds of inference. The validity or lack of validity in an argument largely depends on the form of the statements in which the argument is presented. Epistemology becomes concerned with language at a number of points, especially prominent is the problem of a priori knowledge. We have a priori knowledge when we know something to be the case on some basis other than our experience. Mathematics is one form of this type of knowledge. The existence of a priori knowledge has always been a problem for empiricists.

Verbal discussion is the chief tool of the philosopher, and there are various arguments against language. Advocates of mystical intuition, notably Plotinus and Bergson, have 
considered language to be unsuitable for formulation of truth; however access to truth is intuitively felt or experienced via language forms. Language acquisition of children requires more than simple empirical explanation. So it makes sense to ask if ordinary language is sufficient for philosophical purposes. The later Wittgenstein seems to have held that key philosophical problems arise from the fact that philosophers have misused certain key terms such as “know," "see," “free," and "reason." Thus, they have become entangled in insolvable puzzles over whether we can know what other people are thinking or feeling and whether we can ever really see physical objects. Note that here we are on the way to a post-modern denial of access to "authorial intentionality." (e.g., Rorty, Fish, Layotard, Quine, Bernstein, etc.).

Are issues about the adequacy of ordinary language for philosophical purposes due to language's vagueness, ambiguity, context dependence and inexplicitness? These issues are expressed in the work of Leibnitz, Russell and Carnap. To these men mathematics is the only medium where linguistic defects are overcome. These authors say that there is nothing in one language that one cannot say in any other. Postmodern critics claim that Western culture derives from Aristotle, so Logic and Geometry are purely Western constructions.

Considerable work in Modern and Post Modern philosophies is based on "Conceptual Analysis". When conceptual analysis criticises concepts of causality, the very rationality of the discussion arises. Is language analysis adequate as a tool for the whole of philosophy? What is the relationship of the philosophy of language to the theory of knowledge? What is the meaning of any word? Is there any difference between the statement, "I know" and "I believe?" The need for a functioning methodology for semantic investigation makes it inevitable that analytical philosophers turn their attention to problems of the philosophy of language. Some semantic problems that are prominent are:

1) What is it for a linguistic expression to have a certain meaning?

2) Under what conditions do two or more linguistic expressions have the same meaning?

3) Under what conditions are we justified in saying that a word has two different senses in two different given contexts?

4) What are the conditions under which the meaning of an expression may be more or less vague?

5) What is the difference between a literal and a figurative use of a term?

6) What kind of meanings are there? For e.g., is there a difference between cognitive and emotive meaning?

7) What does it mean to "know?"

8) What is the relation between the structure of language and the structure of whatever it is used to specify?

9) What are the varieties and interrelations of linguistic acts and uses of language?

10) What are the specific features of the language of religion, poetry, normal discourse, advertisement, misinformation, lying under oath, etc.?

11) What are the specific features of different kinds of expression, e.g., proper names and definite description (e.g., difference between description and explanation)?

If we have sufficient basis to infer that language is just a codification of a system of signs that represents experienced reality and, hence in the final analysis cannot have a one-to-one correspondence with this experienced reality, then we cannot doubt that 
language turns out to be information and an expression of the speaker. And this is independent of the truth value contained in propositions. The three terms Beauty, Goodness, Truth (kalon, agathou, aletheia) form a separate subgroup within the general family of Platonic transcendental ideas and their development can be considered separately. Of these three, truth is most closely associated with the topic of this paper and depends solely on propositions. There are two rival theories: correspondence and coherence. For correspondence theory, truth is a relational property involving a specific relation to some portion of experienced reality. For Russell (1912, 129): “Thus a belief is true when there is a corresponding fact, and is false when there is no corresponding fact". Bertrand Russell explained the correspondence theory elegantly and to sum up the theory, it simply states that a belief, statement, or proposition is true if and only if it corresponds with facts (Russell 1912, 119-130). For instance, the statement 'Russell wrote the Problems of Philosophy' is true if and only if it is indeed the case (a fact) that Russell wrote the problems of philosophy. Even though truth-values apply to propositions and beliefs, it also depends on the experienced world. Russell gives the following example, “Othello believes that Desdemona loves Cassio." In that sentence there are two relations. The first one, there is a relation between Desdemona and Cassio that is tied by love. Then, there is the relation between Othello and complex relation signified by the belief. Now, in order for Othello's belief to be true, complex relation (Desdemona loves Cassio) must be a fact. The belief is false if complex relation is not a fact. Russell's correspondence theory is considered to be a realist account because Russell argues that even though truth and falsity apply to beliefs and propositions, truth is still dependent on how reality really is. It depends on facts that are mind and language independent. For instance, the statement "Russell wrote the problems of philosophy" is true if and only if it is indeed the case (a fact) that Russell wrote the problems of philosophy and that fact is independent of language and mind.The authors have adopted a modified theory of correspondence in which following the insights of radical constructivism, we recognize that we cannot get beyond experience to check reality itself, rather we make the best intersubjective viable model of experience.

\section{FORMALIZED AND NATURAL LANGUAGES}

Personal use of language, that constitutes speech, is subject to language rules as a system and to a constant dynamism and fluency with continuous generation of grammatical forms. If speech were to abide by grammar and the prearranged lexicon, the limitations of our communication possibilities would be such that would lead to depersonalization. There would be an overwhelming similarity in our spoken language. The variation in grammatical form possible in everyday language becomes a multiplier of expressive and informative possibilities for the subject, and ultimately, is a source of our forms of verbal behavior, that are structured by grammar to present any actual contribution. Structural linguistics and generative grammar focus on one dynamic and functional grammar.

If any grammar problem arises in order to build a logical syntax the speech will naturally be edited, unless it becomes a form of unusual colloquial speech. But in this case, the use of grammar is not too helpful either, since logic and grammar do not have to be in concert. But if speech is interesting as an expression of the speaker and as a possible source of analysis of specified attitudes, then unusual speech is shown to be extremely useful. As Otero (1989) says "linguistics of the future may well be called upon to be a general theory of human intelligence and its products, and will have to 
give in some way a reason for the difference in nature between an aberrant sentence (e.g. "being tired has feathers") and a false sentence (e.g. "two plus two equals seven'). If natural language would serve effectively to denote experienced reality on a one to one relationship, the function of grammar would lie in making possible the verbal formulation of real processes as accurately and faithfully as possible. But if the two systems are not isomorphic but are heterologous systems then linguistic analysis will be more appropriate for categorizing a corpus of language than natural language grammar. Wittgenstein put it this way: "An expression has meaning only in the stream of life"1. For the denotation of experienced reality is precisely other language, formalized language. The main task of language is subordinate to experienced facts and their relationships. The logical syntax of language (Carnap, 1942) is a field of linguistic research which ignores language users and the designate of linguistic expressions; a theory that is not concerned with the meanings of the terms, but with the classes and hierarchies of symbols that form such expressions. If formalized language, with which it would be possible to express relationships within the context of previously defined speech, is not useful for operational use, than it seems contradictory that a grammar, starting from natural language, should try to give the speech the same status as language using categorical crystallized forms (Russell, 1948). The fundamental issue, therefore, should move from an emphasis on the grammatical categories of parts of speech, to a semantic analysis of syntactic behavior. When Whitehead (1979) wondered if his perception of green is a denotation of reality (green in certain reality) he probably ignores that green is a designation that is absent in some natural languages such as Korean. We could bring up here to emphasize the importance of the radical constructivist perspective also the known discrepancies between the denotations and connotations of colors between the Welsh and the Danes, or the number of words that the Japanese have to designate "wind".

Language as system turns out to embody unwanted but necessary contractions of communication possibilities. Or in other words: language itself limits its functions, its operability. For this reason, Quine (1960) recognized, when dealing with translation that indeterminacy also affects the problem of the reality of objects specified by any term. To verify the accuracy of a lexeme from their translation into another language it is imperative to recognize the reference made in the native language. Hence, the semantics of the reference only make sense if it is oriented toward the original language, i.e., if it is studied from the original statement (Quine, 1960). No cannot understand the intended meaning of a proposition - as reference - other than from standing within the context in which this proposition was given. If it is possible to construct rules to understand the context, then academic grammar is of little use.

\section{INFORMATION AND EXPRESSIVENESS}

The operation prior to the detection of a meaning of denotative significance is the expressive or informative categorization of this significance. In fact, in talking one refers to an object. This object is called the designatum or referent in the usual theory of meaning. The significant issued for the receiver are of two types: director significant A (Nescolarde-Selva and Usó-Doménech, 2014ª,b; Usó-Doménech and Nescolarde-Selva, 2012) and indirect or significant B (ibid). It may be that the direct significant concerns

${ }^{1}$ Ein Ausdruck hat nurim Strome des Lebens Bedeutung. 
an experienced external object (when referring to something or someone), or an internal object (when referring to himself). In any case, also there is a dialectic opposition between both significants. Then:

Hypothesis 1: If one speaks directly about an experienced external object, one speaks directly about this object; if one speaks directly about oneself, the external components are indirectly alluded.

Urban (1951) divides communication acts into two main categories: acts that communicate with a certain behavior or an emotional state (behavioral communication), and acts that confer some knowledge or a mental state (intelligible communication). Ogden and Richards (1989) established the basic distinction between referential terms (or symbolic), i.e., alluding to the referent, and emotive terms. Morris (1946) in turn divided communication into identifiers and designators on one hand, and appreciators and specifiers on the other. The thesis of the double denotative significance (d-s), expressive and informative, confers possibilities that are characteristic of communication. However, this duplex structure of language is not always noticed by the receiver, not even by the sender. Thus, the sender may be unaware of the expressive part of what is communicated and believes that he was only reporting. At the same time, for the receiver, there is always or almost always a plus in this expressed but unnoticed part of the communication. But in our judgment; we do not Consider these two forms of communication, informative and expressive, as independent. In general, it can be thought that the surface structure of any communication corresponds to the informative message and the deep structure to the expressive content. But this is not always the case. In fact, it often happens that propositions have a fundamentally expressive intention rather than intending to conceal information. For example, cases where this occurs directly conceal the emotion of the sender from the receiver, which is typical of populist political messages. In any case, between information and expression there is a dialectical opposition, under which lies the denotative significances as equipollent formations. Then:

Hypothesis 2: Higher expressive content implies lower information content. Higher information content implies lower expressiveness.

So sometimes what is reported includes the hidden structure of communication, while in others it is the expressive content that is hidden under the guise of what is reported.

Definition 1: The informative denotative significance $(\mathrm{d}-\mathrm{s})_{\mathrm{i}}$ is defined as that significance concerning the proposed referent.

Note 1: (d-s) is independent of any referent that is an experienced external object or person speaking.

. A proposition with informative denotative significance is defined by the meaning intended.

Example 1: The following propositions are $(\mathrm{d}-\mathrm{s})_{\mathrm{i}}$ :

1) $\mathbf{P}_{\mathbf{1}}=$ I'm sad

2) $\mathbf{P}_{2}=$ This painting I find beautiful 
3) $\mathbf{P}_{3}=$ This notebook has a red cover

Definition 2: The expressive denotative significance $(\mathrm{d}-\mathrm{s})_{\mathrm{x}}$ is defined as that significance, intentionally alluding to the subject of the proposition, without the subject himself being at that time in the referent of the proposition.

Note 2: $(d-s)_{x}$ are denotative significances not consciously referring to the subject of the proposition.

Note 3: $(d-s)_{x}$ not to be roughly confused with judgments about the referent; as long as the subject of the proposition is aware of its verification as such, the value judgment is a $(d-s)_{x}$.

Example 2: The following propositions are (d-s) $\mathrm{x}$ :

1) $\mathbf{P}_{\mathbf{1}}=$ John's behavior is unbearable

2) $\mathbf{P}_{2}=$ Willows seem to me melancholic ${ }^{2}$

3) $\mathbf{P}_{3}=$ Willows are melancholic ${ }^{3}$

In summary, we can say that:

1) (d-s)i are descriptions, whatever the object, externalor internal.

2) (d-s) $)_{x}$ are self-references, hidden behind the apparent description of the object or referent.

Let $(d-s)_{x}$ be the expressive denotative significance, and $(d-s)_{i}$ be the informative denotative significance. Let (c-s) $)_{\mathrm{x}}$ be the expressive connotative significance and (c-s) be the informative connotative significance. We will use a special formula as a fraction where the numerator is the denotative significances and the connotative significances the denominator. We will represent the two possible cases:

1) Case 1: Expressive denotative significance appears in the foreground as surface structure, while informative denotative significance constitutes the deep structure

$$
\frac{\left\{\begin{array}{l}
(d-s)_{x} \\
(d-s)_{i}
\end{array}\right\}}{\left\{\begin{array}{l}
(c-s)_{x} \\
(c-s)_{i}
\end{array}\right\}}
$$

\footnotetext{
${ }^{2}$ In the proposition Willows seem to me melancholic, the speaker noted that the value judgment is subjective, not a Willow property, so that this proposition is constituted as informative about the speaker, not the willows.

${ }^{3}$ The proposition Willows are melancholic, seems to refer to the willows, when in fact it expresses something about the speaker, although that is not the intention. In it the subject of the proposition aims to inform about the willow, when in fact it only expresses the speaker's feeling.
} 
2) Case 2: Informative denotative significance is in the foreground, absorbing almost all the expressive denotative significance.

$$
\frac{\left\{\begin{array}{l}
(d-s)_{i} \\
(d-s)_{x}
\end{array}\right\}}{\left\{\begin{array}{l}
(c-s)_{i} \\
(c-s)_{x}
\end{array}\right\}}
$$

Example3: For case 1, $\mathbf{P}=$ well, I think ... I do not know ... come, I think it's normal. For case 2, $\mathbf{P}=$ I do not think this is right at all.

Specific analyses of propositions lead us to extensional formulations, representing polipropositional chains (PC) which are enunciated. Then:

$$
\begin{gathered}
P C=\frac{\left\{\begin{array}{l}
(d-s)_{x} \\
(d-s)_{i}
\end{array}\right\}^{1},\left\{\begin{array}{l}
(d-s)_{x} \\
(d-s)_{i}
\end{array}\right\}^{2},\left\{\begin{array}{l}
(d-s)_{x} \\
(d-s)_{i}
\end{array}\right\}^{3}, \ldots \ldots \ldots . . .,\left\{\begin{array}{l}
(d-s)_{x} \\
(d-s)_{i}
\end{array}\right\}^{n}}{\left\{\begin{array}{l}
(c-s)_{x} \\
(c-s)_{i}
\end{array}\right\}^{1},\left\{\begin{array}{l}
(c-s)_{x} \\
(c-s)_{i}
\end{array}\right\}^{2},\left\{\begin{array}{l}
(c-s)_{x} \\
(c-s)_{i}
\end{array}\right\}^{3}, \ldots \ldots . . .,\left\{\begin{array}{l}
(c-s)_{x} \\
(c-s)_{i}
\end{array}\right\}} \\
P C= \\
\left\{\begin{array}{l}
(d-s)_{i} \\
(d-s)_{x}
\end{array}\right\}^{1},\left\{\begin{array}{l}
(d-s)_{i} \\
(d-s)_{x}
\end{array}\right\}^{2},\left\{\begin{array}{l}
(d-s)_{i} \\
(d-s)_{x}
\end{array}\right\}^{3}, \ldots . . .,\left\{\begin{array}{l}
(d-s)_{i} \\
(d-s)_{x}
\end{array}\right\}^{n}
\end{gathered}
$$

Thus, expressive or informative denotative significance corresponds to their connotative significances, of onekind or another.

Example 4: Let's take as an example of our work the attitude of the subject in front of a painting (Figure 1) 


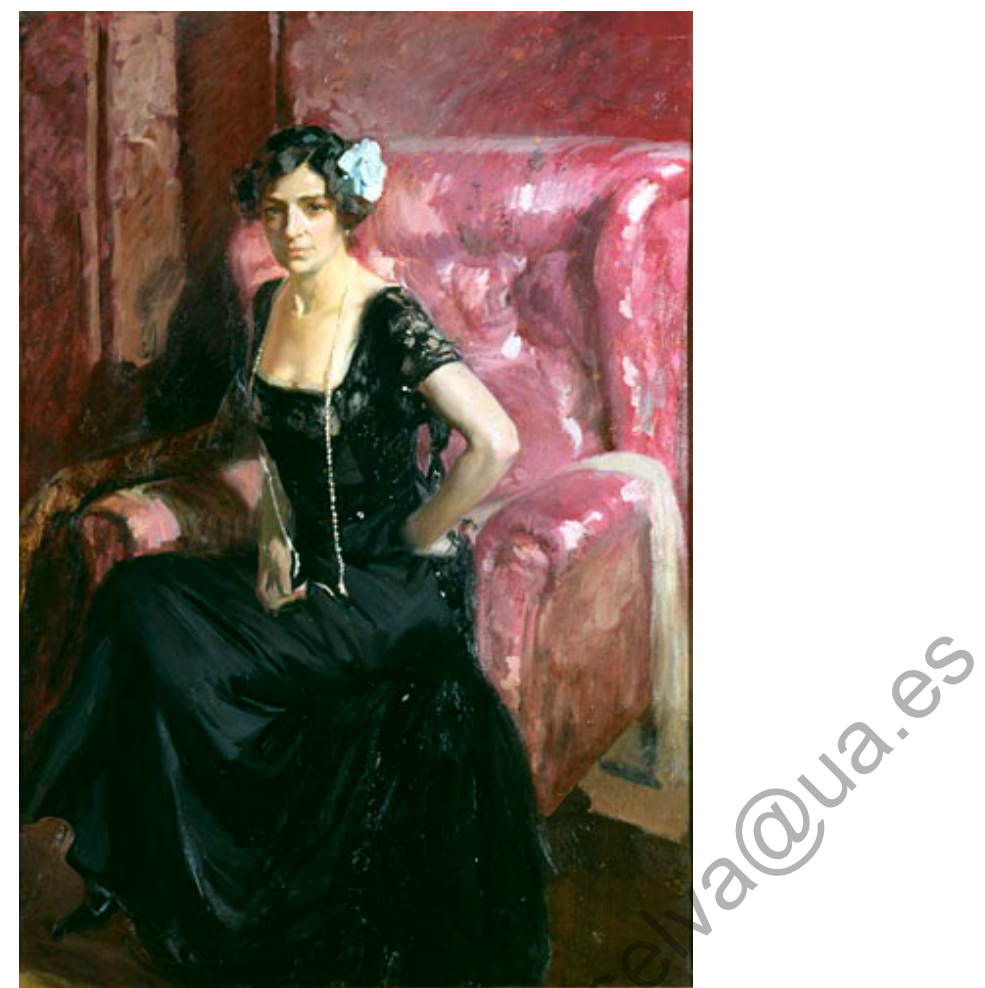

Figure 1: Clotilde in evening dress (Joaquin Sorolla ${ }^{4}$ )

Here is a description of this picture: This is a woman sitting in an armchair, with one hand on her hip and the other holding a pendant. Her eyes look focused. On one of the arms of the armchair hangs a shawl. There seems to be a screen behind the armchair. In this chain of propositions or rather descriptions there appears to be no more than the surface structure consisting of the information provided. From the quantum of seen and unseen reality little can be inferred about the subject's attitude towards the object.

In general, any incorrect or partial reality constitutes an expressive denotative significance of an informative proposition.

Now consider another description of the same picture: This is a woman who is sad, thoughtful, and does not know what to do with the pendant. Her eyes are melancholic. She is disoriented in her life.

None of the partial propositions adduced are categorically informative, except for the reference to "this is a woman". However, the subject, with all the additional content, creates and provides information on the woman in the picture. But really, all he does is projects onto the object of the picture his own attitudes, and consequently what is expressed is his own subjectivity.

The significance of making a polipropositional chain, each part in turn capable of isolation, offers the obvious advantage of making changes in the formalization of phrases in the categories of expressive and informative communication. Returning to the example of figure 1: in the series of following propositions: Well ... this is, how

\footnotetext{
${ }^{4}$ Joaquín Sorolla y Bastida (27 February 1863 - 10 August 1923) was a Valencian Spanish painter. Sorolla excelled in the painting of portraits, landscapes, and monumental works of social and historical themes. His most typical works are characterized by a dexterous representation of the people and landscape under the sunlight of his native land.
} 
would say I? ...., a portrait of a woman as absent. Performing a propositional analysis we would have:

1) $(d-s)_{x}^{1}=$ Well

2) $(d-s)_{i}^{1}=$ this is

3) $(d-s)_{x}^{2}=$ how would say I?

4) $(d-s)_{i}^{2}=A$ portrait of a woman

5) $(d-s)_{x}^{3}=$ as absent

Let $\oplus$ be the operation of propositional addition. Then:

$$
P C=(d-s)_{x}^{1} \oplus(d-s)_{i}^{1} \oplus(d-s)_{x}^{2} \oplus(d-s)_{i}^{2} \oplus(d-s)_{x}^{3}
$$

Definition 3: We define total range $\mathrm{R}$ of a propositional chain, as the number of denotative significances of the chain.

The previous propositional chain has a total range $\mathrm{R}=5$.

Definition 4: We define partial range as the number of expressive $\left(R_{E}\right)$ or informative $\left(R_{I}\right)$ denotative significances of a propositional chain.

In the former case the partial expressive range is $\mathrm{R}_{\mathrm{E}}=3$ and the partial informative range $R_{I}=2$.

Definition 5: A propositional chain will be consistent if the denotative significances maintain the same informative and expressive partial ranges over a certain part of the speech. Otherwise, we say that it is inconsistent.

Thus we can distinguish between expressive or informative consistency (or inconsistency) in a given speech. By way of example we will point out two cases of inconsistency very common in speech.

1) The case of a person whose speech is shown to be consistent with a certain listener and inconsistent to another, to the extent that the latter creates an inhibitory and difficult situation. This manner of speech is very often exploited by leaders of certain movements, both political and religious.

2) Most people can display consistent speech in the context of very varied contents, and at one point, display more or less inconsistency. In such cases, the speaker appears inhibited in communicating, and the speech becomes highly expressive, and does not seem able to give complete expression like the earlier consistent communication.

This schematic representation of the propositional chain allows observing the existence of blockingsof (d-s) $)_{x}$ or $(\mathrm{d}-\mathrm{s})_{\mathrm{i}}$, that sometimes occur from the beginning, and sometimes in the course of the spoken chain. The consideration of blockages shows that the deep 
structure of speech does not necessarily correspond to $(d-s)_{x}$, but other times, what is hidden are all sorts of (d-s)i.

It is often the case with a speech that begins with a propositional chain of expressive significances, switches suddenly the whole structure of the speech and introduces a chain of informative significances. Consider another subject before the painting of the figure 1. His message is: Yes ..., that is ..., maybe I am being foolish ... I do not know ... well ... this is the portrait of a woman dressed formally. "Well" is a verified formal speech inflection, and what follows gains in grammaticality and information.

Definition 6: Those lexemes, which indicate speech, change from expressive denotative significance to informative or vice versa, we will call speech inflection points.

In the above case we have:

1) Expressive propositional chain $=[$ Yes ..., that is ..., maybe I am being foolish ... I do not know ...]

2) Speech inflection point $=[$ well ... $]$

3) Informative propositional chain $=$ [this is the portrait of a woman dressed to be formal]

It is important in propositional analysis to detect when inflection of significance categories occurs.

\section{OSTENSIVE AND ESTIMATIVE PROPOSITIONS}

Let $\mathrm{PC}$ be a chain of propositions such that $P C=P_{1} \oplus P_{2} \oplus P_{3} \oplus \ldots \oplus P_{w}$.

Definition 7: Each of the propositions that form the chain PC we will name partial propositions and will be denoted as $\mathrm{P}_{p}$.

Definition 8: Each partial proposition will be assigned a truth value $V$, such that the value will be 1 if the proposition is true and 0 if false.

Then:

$V\left(P_{p}\right)=$ Sif true

$V\left(P_{p}\right)=0$ if false

\subsection{Ostensive propositions}

There is a category of lexemes and, in general, meaning units that play an ostensive function (Nescolarde-Selva, Usó-Doménech and Gash, 2013), which are extensions of ostension itself, i.e., simple signage. For Quine (1960), these lexemes are extensions of demonstrative pronouns "this", "that", etc.

Definition 9: These lexemes that function as verbal pointers of referents, and are located in experienced reality or imagination, as well as external to the speaker, are called ostensives. 
Ostensive significances have ostensive meaning iff they allude to an external referent, that is, if they make a proposition such as: "it is true than for A this is $p "$.

Note 4: Therefore, for ostensive propositions $(O P)$ we apply the principle of verification in its strict formulation since they are empirical propositions.

Note 5: Ostensive propositions are synthetic judgments and, as stated, are apophantic ${ }^{5}$.

What connotes an ostensive proposition is the situation of the speaker with respect to the referent, or the nature of his apprehension, qualitatively or quantitatively, to the reality that in that moment is a referent. The generic meaning of ostensive propositions is as follows:

1) The existence of the object serves as a reference. It is the categorization, as the real process of the content of the proposition; in this case the content is an ostensor or indicator.

2) The form of apprehension of what is considered real.

Therefore, ostensive propositions connote:

1) Anything that somehow refers to the sender's conception of reality.

2) The way in which the sender (speaker) is close to what he considers as real.

Ostensive propositions are therefore true or false, as they correspond to the referent that they cause. Then, for a given context:

$$
\begin{aligned}
& V(O P)=1 \text { if true } \\
& V(O P)=0 \text { if false }
\end{aligned}
$$

Example 5: Consider the ostensive proposition $\mathrm{OP}=$ the woman is sitting in an armchair. $\mathrm{V}(\mathrm{OP})=1$ iff the woman is sitting in an armchair, i.e., if it is tautological.

From a logical point of view we say that an ostensive proposition has ostensiveness regardless of its truth value.

\subsubsection{True ostensive propositions}

True ostensive propositions $\left(\mathrm{OP}^{\mathrm{V}}\right)$ provide a specific way, a significance with respect to the sender: what thing or things of reality are denoted. From the fact of the denotation of the thing the sender becomes visible, within the set of processes of reality. The propositions cannot be conceived as emerging spontaneously, but must be imagined as a result of the stimulus-response relationship. Therefore, the nature of the response allows one to infer the selectivity identified by the subject of the proposition within the set of perceptual stimuli received.

\footnotetext{
${ }^{5}$ Apophantic is a term Aristotle coined to mean a specific type of declaratory statement that when examined itself can determine the truth or falsity of a logical proposition or phenomenon. It was adopted by Edmund Husserl and Martin Heidegger as part of phenomenology. Marcuse defines it as "the logic of judgment".
} 
Example 6: Consider the ostensive proposition $\mathrm{OP}^{\mathrm{V}}=$ she is a woman who is here sitting, alone. This proposition not only refers to the perceived and denoted, but also what is not described (armchair, shawl, pendant, screen, etc...). The immediate connotation is: between perceived realities, the one that takes human form is especially enticing for him, the nonhuman details remain to be grasped.

In true ostensive propositions $\left(\mathrm{OP}^{\mathrm{V}}\right)$ one is interested in, apart from its total character $\left(\mathrm{OP}^{\mathrm{V}}\right)_{\mathrm{T}}$ or partial character $\left(\mathrm{OP}^{\mathrm{V}}\right)_{\mathrm{P}}$, the following:

a) The content of what makes up a real and true percept.

b) The content of what ceases to be a percept, despite being located in the same perceptual field.

Example 7: Consider that facing same painting an individual issued the following chain of propositions: $\mathrm{PC}=\left(\mathrm{OP}^{\mathrm{V}}\right)_{\mathrm{T}}=$ a seated woman, dressed in black ... and d shawl ... and there is also as a screen. We divide this into partial propositions:

$\left(\mathrm{OP}^{\mathrm{V}}\right)_{\mathrm{P} 1}=$ a seated woman

$\left(\mathrm{OP}^{\mathrm{V}}\right)_{\mathrm{P} 2}=$ dressed in black

$\left(\mathrm{OP}^{\mathrm{V}}\right)_{\mathrm{P} 3}=$ and a shawl

$\left(\mathrm{OP}^{\mathrm{V}}\right)_{\mathrm{P} 4}=$ and there is also as a screen

They tell us about the way the person appends the form of the referent. There is no link between the propositions. The subject is approaching reality in a way that is not global, but rather, from the beginning, punctiform (Figure 2).
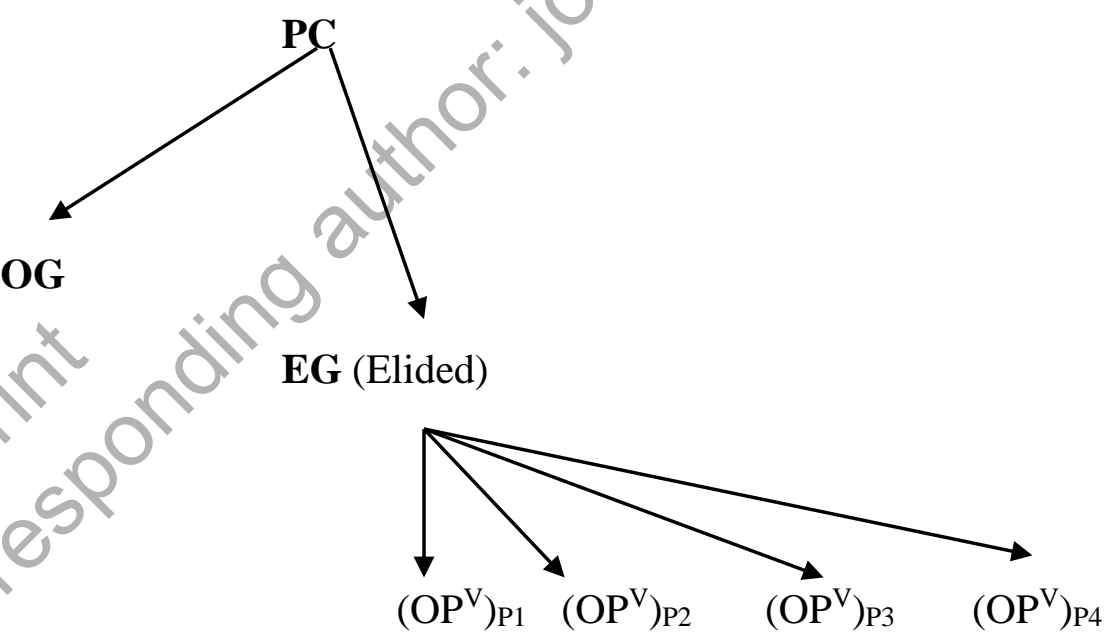

Figure 2: Tree diagram of the proposition of Example 7.EG is the elided group $O G$ is the sentence group

True ostensive propositions $\left(\mathrm{OP}^{\mathrm{V}}\right)$ provide information on the object or referent: expressed in the form of interest about the object. For total true ostensive propositions $\left(\mathrm{OP}^{\mathrm{V}}\right)_{\mathrm{T}}$ the information about the referent is pretty exhaustive, one that barely has a place for expressive significance, except the connotation of being a subject capable of apprehending this part of reality. However, an objective relationship with a plot of reality does not guarantee objective relations to other plots. Therefore, from $\left(\mathrm{OP}^{\mathrm{V}}\right)_{\mathrm{T}}$ we can only infer that the reference field referred to is not a cause of conflict. 
In partially true ostensive propositions $\left(\mathrm{OP}^{\mathrm{V}}\right)$ p revealing the preferential and the optional on certain aspects of reality allows us to connote certain transfers on that plot that are selected and that others are overlooked.

\subsubsection{False ostensive propositions}

A false proposition ostensive remains ostensive, insofar as the sender gives it the quality of ostensiveness because of its function.

Example 8: Consider the proposition $\mathbf{O P}=$ the woman is in the presence of God. It is a false ostensive and the character of the speaker is clear from the formulation, but it is quite unverifiable.

Ogden and Richards (1989) argue that the best test for determining whether a proposition is symbolic is that one could answer whether it was true or false. False ostensive propositions pose a more complex problem. They do not have the same range if falsification comes from an observable referent or if they allude to anunobservable referent.

Example 9: Consider an isolated old mansion; sinister-looking on a stormy night. It is home to two subjects. Suddenly there is a clatter on the glass of a window on the first floor. To $S_{1}$ "it is the rubbing of the branch of a tree on the glass of the window due to the wind". To $\mathrm{S}_{2}$ "it is a vampire who wants to come in". Consider that $\mathrm{S}_{1}$ is impeded and cannot go upstairs. The most plausible reason is that he cannot verify the ostensive, and consider whether it was in fact false, and there is no tree branch. Certainly, these are two different ways of falsifying. For $S_{1}$ nevertheless, he can argue that is in the plane of the observable. For $S_{2}$, there is a slide towards the unobservable level. Various connotative significances are possible for both types of false ostensive, but they are not as different as it seems at first. Note that $S_{1}$ has had the option to say:

a) Is it a tree branch?

b) Can it be a tree branch?

among other propositions. The declarative nature of the proposition has been given on an observable referent but it is not verifiable. Consider that $\mathrm{S}$ had the option to leave things as they are, that is, to the mere verbal encoding of extralinguistic process, such as:"is a noise up there", that would be the only ostensive legitimate proposition.

From overcompensation we can derive dogmatic attitudes very similar to those inherent in subjects able to build false ostensives by appealing to unobservable referents, such as gods, vampires or ghosts. Although experience confirmed the veracity of the ostensive proposition, given as true for a not verifiable referent, which would have modified previously deducted connotations.

Total false ostensive propositions $\left(\mathrm{OP}^{\mathrm{F}}\right)_{\mathrm{T}}$ are connotatively inhibitory for a referent, in a way that incapacitates the subject for objective apprehension in his context.

Example 10: Consider the proposition "this, ... I do not know .... I do not know what this is ... I cannot say anything”.

Propositions like the above do not cease to be ostensive by being in the negative. They denote a disability in awareness of the apprehension of the real, despite repeated efforts 
to capture reality. Partial false ostensive propositions $\left(\mathrm{OP}^{\mathrm{F}}\right)_{\mathrm{P}}$ denote a sectorial apprehension mode of apprehending a totality, and secondly, connote through obtained falsifiability.

Example 11: Consider a subject face the painting of Sorolla. "Here's a woman ... what is this? ..., this is an old cloth ... it seems right? Thinking there.... What I see is what I say."

The following diagram (Table 1) summarizes the foregoing ostensive propositions.

TABLE 1

Characteristics of ostensive propositions

\begin{tabular}{|l|l|}
\hline PROPOSITIONS & \multicolumn{1}{|c|}{ OSTENSIVES (OP) } \\
\hline True Total & $\begin{array}{l}\left(\mathbf{O P}^{\mathbf{V}}\right)_{\text {T }} \text { are objective relations } \\
\text { to the total referent, leaving } \\
\text { the proposition or } \\
\text { propositions verbalized. }\end{array}$ \\
\hline True Partial & $\begin{array}{l}\mathbf{( O P}^{\mathbf{V}} \mathbf{)} \text { are objective relations } \\
\text { with partial reference and } \\
\text { hiding object relations on the } \\
\text { perceived and unperceived. }\end{array}$ \\
\hline False Total & $\begin{array}{l}(\mathbf{O P}) \text { T is object relations with } \\
\text { the object reference, and } \\
\text { subsequent inability for the } \\
\text { apprehension of that object. } \\
\text { Conflict situation regarding } \\
\text { the object and the system of } \\
\text { connotative significances that } \\
\text { imply the object. }\end{array}$ \\
\hline False Partial & $\begin{array}{l}(\mathbf{O P}) \mathbf{p} \text { connotes inability for } \\
\text { total apprehension of reality. } \\
\text { Falsifiability on apprehended } \\
\text { sectorial reality, consecutive } \\
\text { to relationship with the } \\
\text { referent object, as a symbolic } \\
\text { expression of an underlying } \\
\text { conflict. }\end{array}$ \\
\hline Blockages & $\begin{array}{l}\text { Connote an inability to simply } \\
\text { face reality. }\end{array}$ \\
\hline
\end{tabular}

\subsection{Estimative propositions}

The analysis of estimative propositions (EP) is of great interest, because they show the bending or transforming that the subject apprehending reality is forced to verify to merge or distance them from that reality (Nescolarde-Selva, Usó-Doménech and Gash, 2013). An estimation or valuation is, for its protagonist, his projection on the referent. A referent is said to be beautiful or ugly, good or bad, etc. But the important thing is whether the sender is aware or not of the projective character of the process that takes place. In other words, if at any time in the process and for all estimation processes, is 
there an awareness or not that this estimation is a projection of the subject on the referent? Then:

1) Indicate in a direct way which sectors of reality the subject behaves knowingly that value judgments are made. In this case we have value judgments. We classify this as $\left(\mathbf{E P}^{\mathbf{V}}\right)$.

2) Indicate on which other sectors the subject behaves inconsistently in applying his own appreciations on a referent. In this case, we have prejudices or false value judgments. We classify this as $\left(\mathbf{E P} \mathbf{P}^{\mathbf{F}}\right)$.

Both judgments and prejudices reflect, in principle, on the referrer or sender. Imagine the real expression of a subject emitter, as the estimation process supposes derepression by the perceived reality that he values, or alternatively put, the attribution of value on any perceived reality enhances accordingly the subject's appreciation of this view of reality. The verbal formulation of our values, value judgments or prejudices, is somewhat of a hiatus in internal censorship-though primarily that comes from outside-censorship 6 .

If we compare $\mathbf{O P}$ (ostensive propositions) and EP (estimative propositions), we see that $\mathbf{O P}$, to denote the object, allows a disguising or hiding the sender while something is indicated verbally. In EP the subject is given in the reference and he is not hidden.

Note 6: Estimative propositions are apodictic proposition $\hat{s}^{7}$.

All EP are connotative. They are situated in the plane of denotation, in order to broadcast information. But do not be fooled by the linear nature of speech, spoken or written. Not taking into account the different categories of sememes, gives the illusion that language is presented as linear and extensive in a single direction ${ }^{8}$. This is not so, unless the proposition is ostensive.But the interference of EP in moving to what is implicit in the verbal function, composed intentionality, is to be regarded as directed to both the referent object and the referrer or speaker.

\footnotetext{
6"Politically correct language" is a sibylline form of internal censorship, "suggested" (imposed) by members of the ruling political class. So, saying what we feel is a particular form of freedom. The resignation to "be free in what I think" is, of course, a poor aspiration.

${ }^{7}$ Apodictic or apodeictic (capable of demonstration) is an adjectival expression from Aristotelian philosophy that refers to propositions that are demonstrable, that are necessarily or self-evidently the case or that, conversely, are impossible. Apodicticity is the corresponding abstract noun, referring to logical certainty. Apodictic propositions contrast with assertoric propositions, which merely assert that something is (or is not) the case, and with problematic propositions, which assert only the possibility of something being true. For instance, "Two plus two equals four" is apodictic. "Barcelona is larger than Valencia" is assertoric. In Aristotelian logic, "apodictic" is opposed to "dialectic," as scientific proof is opposed to probable reasoning. Kant contrasts "apodictic" with "problematic" and "assertoric" in the Critique of Pure Reason.
}

${ }^{8} \mathrm{~A}$ sememe is a proposed unit of transmitted or intended meaning; it is atomic or indivisible. A sememe can be the meaning expressed by a morpheme, such as the English pluralizing morpheme -s, which carries the sememic feature [+ plural]. 
Example 12: Consider that a subject says: this is the painting of a mature woman, tired, embittered and sad. Generally, we tend to consider everything spoken at the denotative level. But the EP happens to be connotations of the OP (a woman) and denotations reflect on the speaker. So ultimately they are connotative significances. This would be clear if the proposition had been emitted in two phases: This is the painting of a woman. And then we wanted to find out the connotations of "a woman" for the speaker, who has been silent about the picture after issuing the OP. We could ask what does that woman mean to you - and get the following answer: a person already mature, tired, embittered and sad.

The following diagram (Table 2) summarizes the foregoing of estimative propositions:

TABLE 2

\begin{tabular}{|c|c|}
\hline \multicolumn{2}{|c|}{ Characteristics of estimative propositions } \\
\hline PROPOSITIONS & ESTIMATIVES (EP) \\
\hline True Total & $\begin{array}{l}\mathbf{E P}^{\mathbf{V}} \mathbf{t} \text { are objective relations synchronous } \\
\text { with the object and himself, that is, value } \\
\text { judgments that affect the whole of his } \\
\text { reality. }\end{array}$ \\
\hline True Partial & $\begin{array}{l}\mathbf{E P} \mathbf{V}^{\mathbf{p}} \text { are sectorial value judgments about } \\
\text { himself and the parcels of experienced } \\
\text { reality in which they appear. }\end{array}$ \\
\hline False Total & $\begin{array}{l}\text { EPF } \mathbf{t} \text { are totalizing trend prejudices and } \\
\text { reveal false consciousness of the subject- } \\
\text { object and secondarily, of the object and of } \\
\text { himself. }\end{array}$ \\
\hline False Partial & $\begin{array}{l}\text { EPF } \mathbf{t} \text { connote the existence of prejudice on } \\
\text { sectors of experienced reality to which the } \\
\text { subject is unable to take an experienced } \\
\text { intersubjective reality. }\end{array}$ \\
\hline & $\begin{array}{l}\text { Connote an inhibition of the subject from } \\
\text { experienced reality as a whole. The } \\
\text { distancing, the impossibility of fusion with } \\
\text { the object is expressed in the form of "not- } \\
\text { worth it". }\end{array}$ \\
\hline
\end{tabular}

\subsubsection{True estimative propositions}

In $\left(\mathbf{E P} \mathbf{V}^{\mathbf{V}}\right)$ the subject is aware that the qualities of the referent are "transferred" from him, as sender, to the object, and that the referent itself does not possess these qualities. Therefore, it is a bending or transformation of the subject himself; because of this, once carried out the judgment in fact is the verification of the referent. This means that when a subject performs an EP, he shows an awareness of his experience of reality and so acknowledges the subjectivity of valuation.

True estimative propositions are as in the following example:

Example 13: $\left(\mathbf{E P}^{\mathbf{V}}\right)=$ Bach is $I$ think the best musician (or the musician that I like most $) .\left(\mathbf{E P}^{\mathbf{V}}\right)=$ Goya is for me the best painter. $\left(\mathbf{E P}^{\mathbf{V}}\right)=$ This building I find beautiful. 
$\left(\mathbf{E P} \mathbf{P}^{\mathbf{V}}\right)$ denote the speaker's awareness about the subjectivity of all value, and also the purely expressive role that it possesses.These propositions communicate the emotional states of the listener, that otherwise would be inane compared to what happens in the interior of the speaking subject. It is no coincidence that subjects adopt colloquial language that is almost formalized, purely indicative for these propositions are careful to avoid any analysis of them. The result is that the continued habit of non-spontaneous speech, indicates only the external character of the values rather than their deeper meaning.

\subsubsection{False estimative propositions}

In the false estimative propositions (EPF) the sender confers to referent qualities his apprehensions and fears. This maybe indicative of a paranoid dynamism, since connotative significance is given to a referent that does not possess it, which is just the subject's connotation, but has been externalized to the object, in a fantastic manner beyond the subject's awareness.

False estimative propositions $\left(\mathbf{E P}^{\mathbf{F}}\right)$ are as in the following example:

Example 14: $(\mathbf{E P})=$ The willow is sad. $\left(\mathbf{E P}^{\mathbf{F}}\right)=$ Wagner is strident. $\left(\mathbf{E P}^{\mathrm{F}}\right)=$ This garden is beautiful.

Therefore, there is a consciousness of experienced reality that is disturbed by the addition of properties to the referent that do not concern it. This disturbance is due to a lack of self-consciousness about the subjectivity of the valuation.

There are times when an $\left(\mathbf{E P}^{\mathrm{F}}\right)$ is followed by an $\left(\mathbf{E P}^{\mathbf{V}}\right)$, denoting a correction process that the sender executes on himself, further complicating the whole process.

Example 15: Consider a subject facing Sorolla's painting. This is the portrait of a sad woman ..., well, I say she can be sad.

Let's considering what differences we can establish between $\left(\mathbf{E} \mathbf{P}^{\mathbf{V}}\right)$ and $\left(\mathbf{E} \mathbf{P}^{\mathbf{F}}\right)$ ? $\left(\mathbf{E P}^{\mathbf{V}}\right)$ enables initiating communication. We will see this clearly in the following example:

Example 16: Consider a conversation between two subjects. The first $\mathrm{S}_{1}$ proposes: $I$ think that conservatives solved the economic crisis $\left(\mathbf{E P}^{\mathbf{V}}\right)$. And $\mathrm{S}_{2}$ responds: Well, I do not. I think they will not $\left(\mathbf{E} \mathbf{P}^{\mathbf{V}}\right)$. Both are making connotations for themselves to the political and economic situation as a form of self-identity. In any case, communication is accomplished and notoriously, could continue, as long as they are kept under the same canon. Simply talk to each other reciprocally; noting their experiential differences, that is an expression of the reality of their respective differentiation. But suppose a third man $S_{3}$ states: Conservatives are the most prepared $\left(\mathbf{E P}^{\mathbf{F}}\right)$. Given this proposition, these two responses can fit: Conservatives are not well prepared $\left(\mathbf{E P} \mathbf{P}^{\mathbf{F}}\right)$, or Conservatives are well prepared for you $\left(\mathbf{E P} \mathbf{P}^{\mathbf{V}}\right)$. Then communication is broken in the sense that a new interpretation is introduced.

Consider (EP) where no discussion is possible: On (EPV $)$ it is possible to communicate opinions, whereas with (EP' $)$ it is only possible to have conflicting opinions. (EPF) involves inflicting a hiatus in the communicative function; this is not useful for 
communication because its function cannot be fulfilled, which does not contradict the fact that it is highly connotative for any subject that uses this form of speech ${ }^{9}$.

$\left(\mathbf{E P}^{\mathrm{F}}\right)$ denotes unconsciousness of the speaker regarding the subjectivity of any value or false consciousness of objectivity of all value. Their internal insecurity compels them to evade any flexible interpretation of reality, implying that flexibility is not amongst the properties reality may possess. In extreme cases speakers are willing to reject the conventional character of every denomination that is not theirs, and are ready to give existence to all that they choose to name ${ }^{10}$. From another perspective, this is clearly a false consciousness of reality. They need an unchangeable reality, where they have a timeless and ahistorical place, described with abstract nouns such as purity, beauty, justice, etc. These values are absolute, and indeed they are the bearers of these same values. Values are not mere moods, but the qualities that are inherent in things. Internal insecurity may be hyper illusory and if so may be compensated for by building a safe, stable and hierarchical world. This insecurity is expressive and may imply a connotative rejection of experienced reality, which is then replaced by a fantastic new constructed reality. Hence the (EPF $)$ property of outsourcing i.e., projected outside the subject, and imposed on the personal reality, is then uncorrectable. (EPF) involves a distorted interpretation that cannot be abandoned because it satisfies profound insecurity. This is the cause of the incorrigibility of prejudice.

\subsubsection{Order of estimative propositions}

Bending moments of estimative propositions are summarized in the following table (table 3):

TABLE 3

Bending moments of estimative propositions.

\begin{tabular}{|c|l|l|}
\hline Steps & \multicolumn{1}{|c|}{ True Estimative $\mathbf{E P} \mathbf{V}$} & \multicolumn{1}{c|}{ False estimative $\mathbf{E P}^{\mathbf{F}}$} \\
\hline 1 & $\begin{array}{l}\text { The referent (absolute being) is } \\
\text { perceived. }\end{array}$ & $\begin{array}{l}\text { The referent (absolute being) is } \\
\text { perceived. }\end{array}$ \\
\hline 2 & $\begin{array}{l}\text { It is noted what the reference } \\
\text { is. }\end{array}$ & It is noted what the reference is. \\
\hline 3 & It is denoted. & It is denoted. \\
\hline 4 & The reference image is valued. & $\begin{array}{l}\text { The reference image is valued } \\
\text { without consciousness of being this } \\
\text { image. }\end{array}$ \\
\hline 5 & $\begin{array}{l}\text { The verified valuation is } \\
\text { connoted. }\end{array}$ & $\begin{array}{l}\text { The verified valuation is connoted as } \\
\text { referent. }\end{array}$ \\
\hline 6 & $\begin{array}{l}\text { The connotation of the } \\
\text { reference image and the } \\
\text { evaluation of the image are } \\
\text { given in concert to the receiver. }\end{array}$ & $\begin{array}{l}\text { The supposed connotation of the } \\
\text { subject and its valuation, as alleged } \\
\text { ownership of the referent, are offered } \\
\text { in concert to the receiver. }\end{array}$ \\
\hline
\end{tabular}

\footnotetext{
${ }^{9}$ Experience shows that the discussion of (EPF) is totally barren.

${ }^{10}$ Correlation between the number of (EPF) and ignorance is testable.
} 
Estimative propositions have different values according to the order that they appear in the propositional sequence.

1) An initial $\mathbf{E P}$ is most likely an $\mathbf{E P}^{\mathbf{F}}$ contributing to the $\mathbf{O P}$ that are to come.

Example 17: This is awful, it is an old woman. The painting of an old woman.

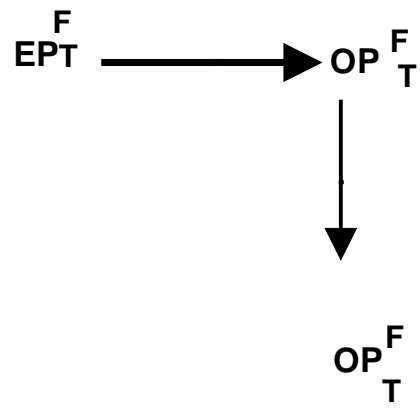

2) A medial $\mathbf{E P}$ is almost always true.

Example 18: The painting of a woman, who appears to be sad, isn't it? ... I see it as sad.

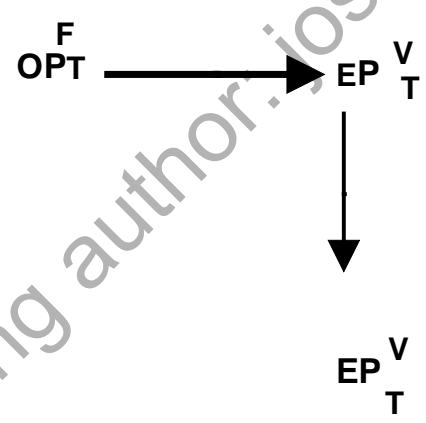

3) A terminal EP is usually true or false depending on the truth or falsity of the ostensive $\mathbf{O P}$.

Example 19:This is a woman, the painting of a woman, with slanted eyes looking tired, hair a little out of place, small nose, I think she has one eyebrow a little higher than other ... Of course she is ugly. 


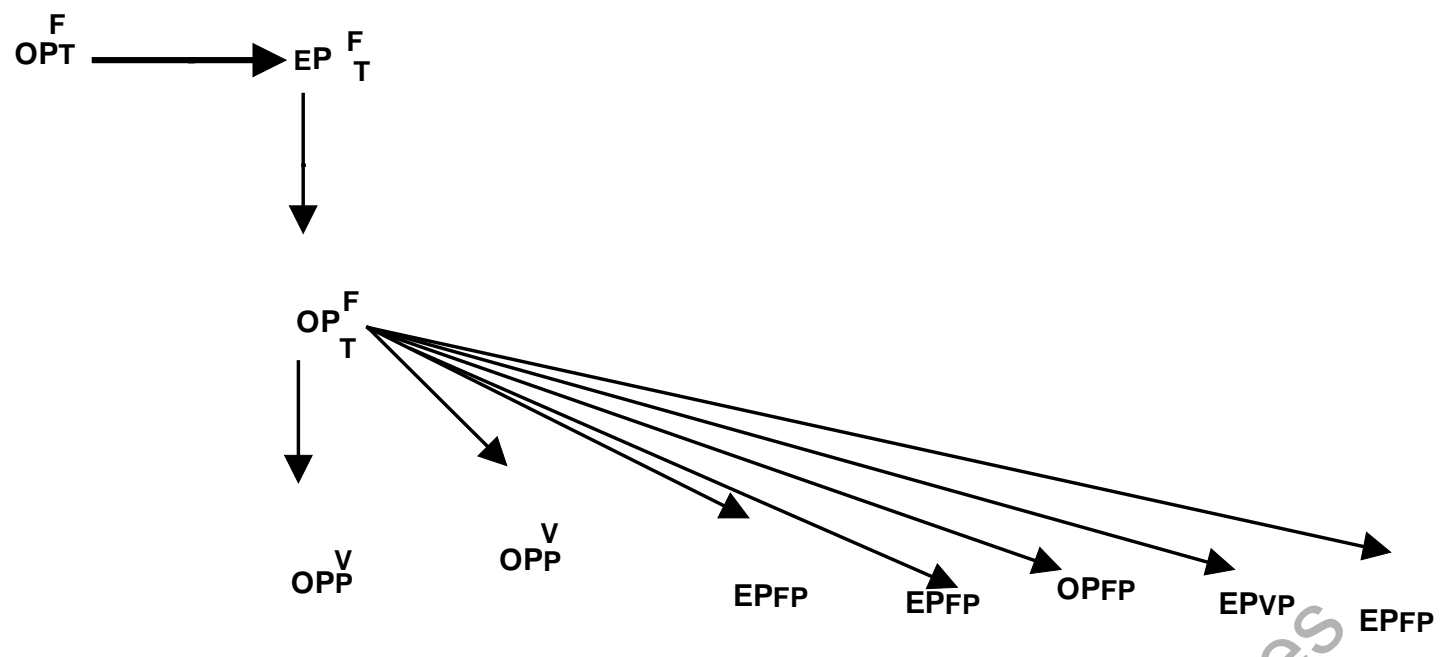

The qualification of a PC as true or false has to be done carefully, and with due regard to its value (in the Saussirian sense of the term) in context. And this is because the speech experience, experience on the interpretation of the other of our speech, has brought subtle learning expression mechanisms, making it possibte to maintain caution. It can be said, very measured sentences often have more biased content, and in this sense diplomatic language, or Vatican language, are interesting examples of expression control.

\subsubsection{Values of veracity}

Proposition 1: All propositional chains have a truth value which is a real number comprised within the range $[0,1]$.

\section{Proof}

Let PC be a propositional chain, $P^{V}$ be the partial true proposition, $P^{F}$ be the partial false proposition, $\mathrm{n}$ be the number of partial true propositions and $\mathrm{m}$ be number of partial falsepropositions. Then:

$$
V(P C)=\frac{\sum_{i=1}^{n} V\left(P^{V}\right)_{i}+\sum_{i=1}^{m} V\left(P^{F}\right)_{i}}{n+m} \in[0,1]
$$

Example 20: We consider the propositional chain of Example 19. We divide the chain in partial propositions such that:

$$
\begin{aligned}
& \left(O P^{v}\right)_{P 1}=\text { This is a woman, } \\
& \left(O P^{V}\right)_{P 2}=\text { the painting of a woman } \\
& \left(E P^{F}\right)_{P 3}=\text { with slanting eyes looking tired } \\
& \left(E P^{F}\right)_{P 4}=\text { hair a little out of placed, } \\
& \left(O P^{F}\right)_{P 5}=\text { small nose, } \\
& \left(E P^{v}\right)_{P 6}=I \text { think she has one eyebrow a little higher than the other }
\end{aligned}
$$


$\left(E P^{F}\right)_{P 7}=$ Of course she is ugly

Then:

$V\left(\left(O P^{v}\right)_{P 1}\right)=1$
$V\left(\left(O P^{v}\right)_{P 2}\right)=1$
$V\left(\left(E P^{F}\right)_{P 3}\right)=0$
$V\left(\left(E P^{F}\right)_{P 4}\right)=0$
$V\left(\left(O P^{F}\right)_{P 5}\right)=0$
$V\left(\left(E P^{V}\right)_{P 6}\right)=1$
$V\left(\left(E P^{F}\right)_{P 7}\right)=0$

$V(P C)=\frac{\sum_{i=1}^{n} V\left(P^{V}\right)_{i}+\sum_{i=1}^{m} V\left(P^{F}\right)_{i}}{n+m}=\frac{3}{7}=0.428 \ldots . . \in[0,1]$

Having a fuzzy truth poses a problem: when can we say that propositional chains are true or false; completely true or false; or partly true or false?

\section{VALUES AND LANGUAGE}

Definition 10 (Usó-Doménech and Nescolarde-Selva, 2012): Values are mental constructions in the mind of the Subject generated by specific forms of conduct due to the actions conducted by a certain group of people, tribe, nation or culture.

For Luhmann (1985) if one can speak of "morality" in the social system, this expression refers to a set of pure conventions (values): The totality of the conditions which this system uses to make estimations of reprobation. In our approach to social systems there are two superstructures (Nêscolarde-Selva and Usó-Doménech, 2013 ${ }^{\mathrm{a}, \mathrm{b}}$, Usó-Doménech and Nescolarde-Selva, 2012):

1) A concrete specific Superstructure formed by diverse belief systems: ideologies, values in fact, philosophy, sciences, etc. We will call this Superstructure the Doxical Superstructure (DS).

2) An abstract ideal Superstructure formed by ideal values, myths, utopia, etc., serving as the primogenetic explanation and the ultimate goal in this structural base. We will call this Superstructure the Mythical Superstructure (MS) (Nescolarde-Selva, Usó-Doménech and Lloret-Climent, 2014).

We summarized these ideas in the following diagram (Figure 3): 


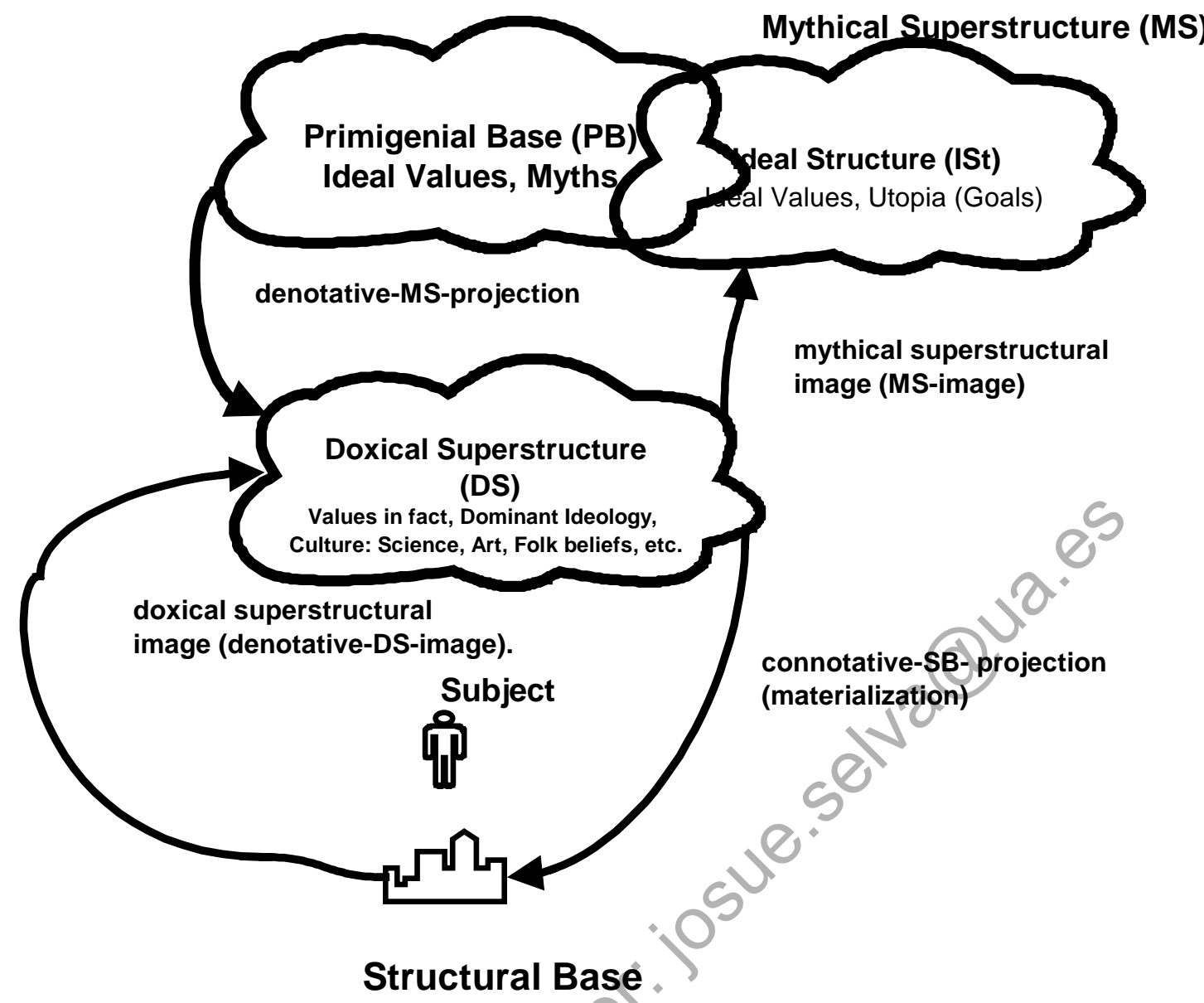

Figure 3: Structures and Superstructures of social systems

For example, the imperative norm "Thou shalt not kill" expresses the value for life, "Thou shalt not steal" expresses the value for property, etc. LeShan and Margenau (1982) call these values values in fact, because they are automatically born of considerations, either as an image or reflection of the structural base in the Doxical superstructure, and do have not innate nor outside obligatory validity except for conformity with the imperative norms that are arbitrary to a great extent. Considering the values in themselves, it is not possible to know if their structural antecedents, the imperative norms, are valid. Values more frequently describe the majority conduct of the group of actor subjects; the practice is taken as a norm. It is thought that determined actions or behaviors are correct if the majority accepts them. This deceit is common and pernicious and lasts until this normative structure changes. Values in fact lack normative force (projection of Doxical Superstructure on Structural Base). Being merely in fact needs to be "should have it". That the "to be" reaches "must be" is through ethical validity. Nevertheless, the added value of the validity supposes the establishment of correspondences with another series of values called ideal values (in the Mythical Superstructure). All normative structures belonging to the Structural Base contain, in addition to norms and their reflection in the Doxical Superstructure in types of values in fact, a series of goals that are the ideal values reflecting the Doxical Superstructure on the Mythical Superstructure. These ideal values are practically accepted in almost all cultures: they contain principles on personal and collective human happiness, freedom of action and beliefs, the right to life, health, tranquility, peace, 
privacy, certain conjugal fidelity rights, education, etc. These ideal values include "Human rights". In spite of the variety of their names, the values are compatible. The correspondence between values in fact and ideal values, the added value of happiness, freedom, etc., by mediation of a life in agreement with these forms of order, are taken to give validity to the Doxical Superstructure, transforming values in fact into norms, by mediation of a projection of the Doxical Superstructure to the Structural Base.

The hermeneutical study of estimative propositions leads to a disturbing hypothesis: the impossibility of objective ethics and aesthetics. An objectivist theory of values, either ethical or aesthetic, argues that these are properties of referents, whether observable or unobservable. However, the thesis of the objectivity of values is a sample of the verbalistic fallacy, where to be is not taken as the copulative verb, but as a symbol of identity, or at least of equivalence. The proposition " $x$ is good" is equal to " $x$ has the property of being good." The objectivist thesis is also called the naturalistic fallacy. By contrast, the subjectivist theory of values, maintains the thesis that value is a subject property verifying the proposition about the object. There is no denying the existence of values, much less their operational nature, but trying to show the subjective its nature, and understanding values belong to the subject or subjects is a difficult task.

Example 21: Consider the proposition this picture is beautiful. It is an estimative proposition, or attributive, regardless of what is shared uniquely or unanimously.

Propositions of this kind are inferences drawn directly from an OP (about this picture), and here lies the incorrect logic. Since if the estimative propositions are denotations of the subject about the proposition, then we are forbidden to make inferences from an $\mathbf{O P}$ that belongs to a different experienced object of reality. In the false valuation, in considering the value as the property of the object, the subject obtains the value as an $\mathbf{O P}$, such as in the following example:

Example 22: This picture is a portrait, pink and black colors are dominant, consisting of a figure, etc.. and beautiful. It is noted that the last proposition is presented as an $\left(\mathbf{O P}^{\mathbf{V}}\right) \mathbf{P}$, when it is an $\left(\mathbf{E P}^{\mathbf{F}}\right) \mathbf{P}$

In summary, we can say that for large OPs that are provided for a referent, the inference of an EP is not permitted, because an EP no longer belongs to the referent object but to the speaker of the proposition, which is another object. The amount of denotations we do on a referent $X$ does not allow transfer to the referent $Y$, simply because they are different referents.

In the EP, i.e., the values, the referent is the referrer. Let $x$ be a referent and $f(x)$ be a function. Let $\mathrm{I}$ be an operator such that $\mathrm{l} x(\mathrm{f}(\mathrm{x}))$ meaning that $\mathrm{x}$ is the referent that satisfies a certain function.

Example 23: Consider the following proposition $\mathbf{P}=$ Moms are selfless. $1 \mathrm{x}(\mathrm{f}(\mathrm{x}))$ reads like the $\mathrm{x}$ Moms are meeting the function $\mathrm{f}(\mathrm{x})$ to be selfless. What procedure is there to discuss the truth or falsity of the predicate of the proposition $\mathbf{P}=$ Moms are selfless? Let

$S$ be a subject (referrer). As the proposition is issued and expressed: $\forall S /\rceil \mathrm{x}(\mathrm{f}(\mathrm{x}))$ ), i.e., for all Subject-Moms are selfless. But if formulated: it is the case that there is at least a 
subject for which Moms are selfless, then $\exists S / \mathrm{T}(\mathrm{f}(\mathrm{x}))$. Their truth values are respectively: $\mathrm{V}(\forall S /\rceil \mathrm{x}(\mathrm{f}(\mathrm{x})))=0$ and $\mathrm{V}(\exists S / \mathrm{Tx}(\mathrm{f}(\mathrm{x})))=1$.

There is no denying the existence of value. The value exists as property of the subject being valued. The truth makes sense for the emitter of the proposition, not for the subject of the sentence. The second propositional form is called existential. This demonstrates the subjective nature of every evaluative proposition and thus, the subjective nature of any value involved in any kind of propositions that contain it.

A system of propositions EP is thus a system of $\mathbf{O P}$ regarding the referrer who therefore can build a system of referential value of their ideology. The value system connotes directly about the ethics and aesthetics of the subject or group, but does not make it possible to build an ethics or aesthetics of generic rank, beyond any historical, cultural and personal relativism. An ethics or aesthetics which it is intended to confer an ahistorical absolute and timeless category, demonstrates the non-theoretical, doctrinal approach of those that support it, and in any case requires interpretation through recourse to economics, sociology and social and individual psychology. Its interpretation leads to the system of connotations' of the subject of the proposition which happen to be comparable to the intrasubjective or extrasubjective motivations of the subject.

\section{LANGUAGE AND IDEOLOGY}

Is necessary to ask the following: what is the mechanism that makes it possible to consider value as the property of an experiencêd object? For the authors, this is due to different learning processes that take place in the subject-object relationship:

1) The verbalist fallacy: One learned the use of words and academic categorizations in total dissociation from their logical categories. The child learns to denote the objects with which he interacts and knows the use of denotations to allude to both visible and invisible referents, and importantly both subjective and intersubjective denotations. Thus, the child acquires the illusion that the words are the objects they designate. In addition, if the words function, the qualities they denote are taken to be as real as the objects to which the word refers. The magical power given to words, especially nouns, resides then in the idea that words can conjure up objects. What the child and the adult also often do is think that the way they think about objects and other phenomena in their experience is that there is only one way to think about these objects and phenomena.

2) Intentional learning: the valuation procedure of words beyond their denotative range is facilitated by adults who often emphasise the right way of feeling thinking and so on as though there was only one perspective. so, the child is constantly confronted with value judgments he cannot validate objectively, but which are presented as statements of fact. "This is good" and "that is bad" are offered to the child just as in saying "this is red" and "that is green." Such submissions become part of "socialized reality", which is one reason why many adults (some great philosophers too) do not accept the logical difference between the moral imperative and the affirmation of fact. The child is made to learn that there are values per se, as a way to facilitate their integration into the 
group holding these values. Having achieved the autonomy of that learning, there is a tendency to keep valuing, individually, because group membership is closely associated with sharing values. Prejudice is a sort of conservation: a cognitive invariance. We think that social conservations of this type are related to self-identity and their expression to self-esteem. Children employ a wide range of rhetorical tools and an understanding of their functions. Speakers understand the power of persuasion, they support their assertions with examples, they use comparisons, playful language, and attempt irony (although the speaker calls it sarcasm), thus indicating their awareness that language is not transparent to meaning. This sophisticated apprehension of language often contrasts with their limited fluency. Sometimes their formulations border on the incomprehensible or appear self-contradictory ('I think handicapped people are no different than we are. They're just people that are different'). The limited linguistic fluency and relatively poor syntax may obfuscate but do nof deny the children's capacity for logical operations and reasoned responses. Children display inter alia their ability to classify, their understanding of the principle of the excluded middle, the fallacy of arguing the universal from the particular. Gash (1993) argued identity is involved because children's known ideas about "out-groups" are the way their "in-group" expects them to think. For example, if a boy suddenly changes his ideas about girls or about his views on playing with a child with Down's syndrome, his friends will wonder why he changed. They thought they knew his ideas about girls. They thought he had similar ideas to themselves about children with Down's syndrome. These may well have been unexamined negative ideas but holding a common view gave them a sense of solidarity. They were different. They were not like that. So what has happened? Why has their friend changed? In this sense prejudices are individual expectations with social implications. They form part of an individual's identity within the group.

A group is held together by ideology (Nescolarde-Selva and Usó-Doménech, 2014 ${ }^{\mathrm{a}, \mathrm{b}}$; Usó-Doménech and Nescolarde-Selva, 2012), and it is defined by the value system that it considers fundamental (Nescolarde-Selva and Usó-Doménech, 2013 ${ }^{\mathrm{a}, \mathrm{b}}$, UsóDoménech and Nescolarde-Selva, 2012) and must be shared by all group members.

The content of the EP provides a useful path, through the vehicle of language about values concerning particular subjects. Much of our values, our substantive beliefs (Nescolarde-Selva and Usó-Doménech, 2013 ${ }^{\mathrm{a}, \mathrm{b}}$, Usó-Doménech and Nescolarde-Selva, 2012), i.e., our EP, we ascribe to a particular social group,precisely one that shares or from which we have received our values, now accepted as our own. A group is constituted as such by the nature of the EP that we share. A group becomes more cohesive, the most closely related though $\left(\mathbf{E P} \mathbf{P}^{\mathbf{F}}\right)$. (EPV) always refers to individual nuances and involves the construction of a world of values, of which some are shared, without prejudice to the possibility that others do not, and corresponds to a personal acquisition as a result of a process of individuation. By contrast, it may mean not giving way to other's reasoning, require indiscriminate and undifferentiated rejection of ideas accepted by others, or ideas that have been provided by those who at the time perform the role of being the hierarchical rank of the group. In the same way $\left(\mathbf{E P}^{\mathbf{F}}\right)$ hierarchize the reality and insist it is necessary to accept the hierarchy of those who are carriers of the "eternal values". (EPF) appeals to unsure and unsafe subjects who can only survive without trouble acting irrationally and doing indisputable damage to their value system. 
They are encouraged to give substantive nature to the values, especially abstract nouns, in so far as they mean the "concept" that encompasses a set of specific adjectives. For the (EPF), beauty, goodness, justice, etc., or superiority, evil, sin, etc.., are set names for things, that in turn are estimated as beautiful, good, fair, etc.., or higher, bad, sinful, etc..

Example 24: There are no biological, historical, social reasons of any kind to justify the following false estimative propositions:

1) Men are superior to women on account of the qualities with which God has gifted the one above the other, and on account of the outlay they make from their substance for them.

2) The Jews are our misfortune.

3) Blacks are an inferior race.

4) There is no salvation outside the Church.

5) Homosexuality is a vice.

6) The left is morally superior.

7) Blood ties are sacred.

These propositions are not just anecdotes but have led to marginalization, discrimination, persecution, exile, torture and extermination of millions of human beings throughout history.

Adopting group values confers, on the other hand, security that socialization implies in the broad sense. One is part of the group as long as one shares their values.Not sharing entails self-condemnation to ostracism, marginalization or, in some cases, persecution and even death. Repression of speech is primarily an extra-subjective process and secondarily lived as one's own experience, through the appropriation of the values of the social and ideological group in which the subject is located. So if the group membership allows certain forms of speech, on the other hand, the adoption of the values of that group, to coexist in it, requires self-limited communication capabilities. In fact, the eventual exit from (if possible) the enabler-inhibitor group, in turn, makes possible certain forms of liberated speech (and in general of behavior), which shows the light repression of everyday environment. Political censorship is exercised, of course, in the realm of information, but value judgments are hidden. Serious political repression, justified from the internal logic of totalitarian systems, is a consequence of making judgments of valuethat cannot be tolerated in any way. This would make us wonder about the concept of "normality". If (EPV $\mathbf{E P}^{\mathbf{V}}$ requires individual responsible judgment, it should be easier to differ from group think. However, paranoid, obsessive, depressive, anxious, etc. dynamisms exist in every individual and depend on the balance or lack of balance between the individual and the group. That the possessors of these clinical conditions become ill or marginalized depends on this balance of the individual with the social system. Being part of the social system and internalizing the ideology of the system itself may provide serious conflicts for an individual who in turn may be considered as having such ills ${ }^{11}$.

\section{CONCLUSIONS}

\footnotetext{
11 In different cultural contexts of the West mystical systems are tolerated and respected, but are considered delusions or paranoid attitudes by people who overestimate real attitudes of the community.
} 
While the philosophy of language has focused on questions of meaning, language use and the relation between language and reality, hermeneutical analysis contributes to the view that interpretive issues in language are paramount. We arrived at the following conclusions:

1) Estimative EP propositions are connotative of OPs which intend to define or qualify, and are denotative of the speaker who aims to define and qualify the object with his speech EPs reflect on the speaker, who is required to verify connotative operations on meanings.

2) The distinction between $\left(\mathbf{E P}^{\mathbf{V}}\right)$ and $\left(\mathbf{E} \mathbf{P}^{\mathbf{F}}\right)$ is extremely important for human communication. Human communication is not comparable to what can be carried out, for example, by traffic signals.In these, there are only indications. Therefore, in subjects whose speech consists only of (OPs), their informational value may be high, but hardly communicative, because communication includes information and expression. A speech consisting entirely of OP is a speech that conceals.

3) Within Freud's and indeed Norbert Elias's theories, civilisation is built on repression. Repression is seen to operate on at least two distinct levels. On one level individuals operate the restrictions on themselves (intra-individual consistency), and on the other, society orchestrates the constraints on the individual (inter-individual consistency). Whilst a collective cannot exist without a shared cultural and ideological system - which each individual will of course adhere to differentially - the logic of individuals submitting themselves to a repressive set of cultural and ideological norms is less clear (Gash \& Gash, 1999). This must be answered in terms of how the individual balances the importance of intra-individual and inter-individual constraints. So what do individuals gain from society that makes people stop acting on their impulses and desires? Is the "reality" principle strong enough (inter-individual consistency)? A tentative answer is that through allegiance to the system the individual accrues security from the system. This can be illustrated microsocially: in so far as a colectivity can live according to a set of norms and values (unified belief system), we can anticipate others' behaviour and actions and consequentially plan and organise our own. Bauman (1997) argues that in our post-moderm society the balance existing between the individual and society, between impulse and security, repression/suppression, has shifted. In a modernist perspective there was a greater emphasis on individuals submitting themselves to the dictates of the social whole. In post-modern society, it is argued that the balance has shifted towards a greater recognition of individual constructions, in other words in post-modern society there are greater capacities for individual freedom. Given the continual dynamic which exists between agency and structure, the implication of greater individual freedom (read: less socially imposed constraint) is greater insecurity (read: less socially negotiated order).

4) The norms and values of a society are clarified and reiterated over time as it becomes recursively more self-aware. A symptom of modernity and of cohesive societies is a pursuit of order according to the dictates of the negotiated ideological system. The implicit pact of civility exists between agents of the system and requires an understanding of and adherence to this pact. This 
assumes both that the other (a) has an understanding of the normative boundaries and (b) is willing to comply with them. The introduction of a different other, hence, can pose a challenge to agreed normative expectations. In other words, individuals strive to balance two types of coherences: interindividual consistency, maintaining a normative coherence between members of the group, and intra-individual consistency, where coherence is maintained within individuals' own ideological systems (Gash \& Gash, 1997). However, tolerance rates in all of these studies change as a result of increased contact with different others. This has been explained by the greater differentiation which occurs with increased contact between self and other. The ethical issue is whether the attitudinal change is positive. At a broader micro-social level, the agreed ways of interacting with others in a group may be set aside if the different other is recognised as such. The educational and social challenge in a post-modern pluralist society is to promote an ethic of mutual respect to ensure tolerance.

5) The analysis of everyday speech, both in its formal aspects as those concerning the content, involves a more differentiated approach to penetrate the ideology of the speaker, and, through it, detect its assignment to groups, and their desire for unachieved affiliation .Despite repression imposed in these forms of speech, there is always some escape route by which the expressive significances emerge to the observer.

\section{REFERENCES}

Bauman, Z. 1997. Postmodernity and its discontents. Cambridge, UK: Polity.

Carnap, R. 1942. Introduction to Semantics. Cambridge. Mass.: Harvard Univ Press.

Ceccato, S. (1961) The machine which observes and describes. University of Milan (Mimeo), Milan.

Gash, H. 1993. A constructivist attempt to promote positive attitudes towards children with special needs.European Journal of Special Needs Education, 8, 106-125.

Gash, H., and Gash, V. 1997. Constructivism and tolerance of difference. In G.E. Lasker (Ed.) Advances in Education. International Institute for Advanced Studies: Windsor, Ontario.

Gash, H., and Gash V. 1999. Constructivism and the ethics of mutual respect. In G.E. Lasker \& V. Lomeiko (Eds) Culture of peace: Survival strategy and action programme for the third millennium. pp. 51-58, International Institute for Advanced Studies: Windsor Ontario.

Glasersfeld E. von (1972) Semantic analysis of verbs in terms of conceptual situations. Linguistics 94: 90-107. Available at http://www.vonglasersfeld.com/022

Glasersfeld E. von (1995) Radical Constructivism. Falmer Press, London. 
LeShan, L. and Margenau, H. 1982. Einstein's Space and Van Gogh's Sky. MacMillan Publ. Co. Inc. New York.

Luhmann, N. 1985. Soziale Systeme. Grundrisseinerallgemeinen Theorie (2 ${ }^{\circ}$ ed). Suhrkamp. Frankfurt.

Morris, Ch. 1946. Signs, Language and Behavior. Prentice Hall: New York.

Nescolarde-Selva, J. and Usó-Doménech, J. 2013a . Topological Structures of Complex Belief Systems. Complexity, 19(1). pp. 46-62. DOI: 10.1002/cplx.21455.

Nescolarde-Selva, J. and Usó-Doménech, J. 2013를. Topological Structures of Complex Belief Systems (II): Textual materialization. Complexity, 19(2). pp. 50-62. DOI: 10.1002/cplx.21476.

Nescolarde-Selva, J. and Usó-Domènech, J.L. 2014. Semiotic Vision of Ideologies. Foundations of Science, Vol 19 (3), pp 263-282.DOI 10.1007/s10699-013-9329-9.

Nescolarde-Selva, J. and Usó-Doménech, J. 2014 ${ }^{\mathrm{b}}$. Reality, System and Impure Systems. Foundations of Science, Vol 19 (3), pp 289-306.DOI: 10.1007/s10699-0139337-8.

Nescolarde-Selva, J. Usó-Doménech, J.L and Gash,H. 2013. A Theorical Point of View of Reality, Perception, and Language. Complexity. DOI 10.1002/cplx.21493.

Nescolarde-Selva, J.; Usó-Doménech, J.L., and Lloret-Climent, M. 2014. Mythical Systems: Mathematic and Logical Theory. International Journal of General Systems. DOI:10.1080/03081079.2014.947977.

Ogden, C.K. and Richards, I.A. 1989. The Meaning of Meaning. With a new introduction by Umberto Eco. Harcourt Brace Jovanovich: Orlando. Florida.

Otero, C.P. 1989. Introducción a la lingüística transformacional. Siglo XXI Editores. México. (In Spanish).

Quine, W. van Orman. 1960. Word and Object. MIT Press: Cambridge Mass.

Russell, B. 1912. Problems of Philosophy. Reprinted at Oxford: Oxford University Press 1971.

Russell. B. 1948. Human Knowledge: Its Scope and Limits. George Allen \&Unwin. London

Urban, W. M. 1951. Language and Reality.George Allen \& Unwind Ltd. London.

Usó-Doménech, J.L., and Nescolarde-Selva, J. 2012. Mathematic and semiotic theory of ideological systems. LAP: Saarbrücken. Germany. 
Whitehead, A.N. 1929. Process and Reality: An Essay in Cosmology. 1979 corrected edition, edited by David Ray Griffin and Donald W. Sherburne, Free Press: New York.

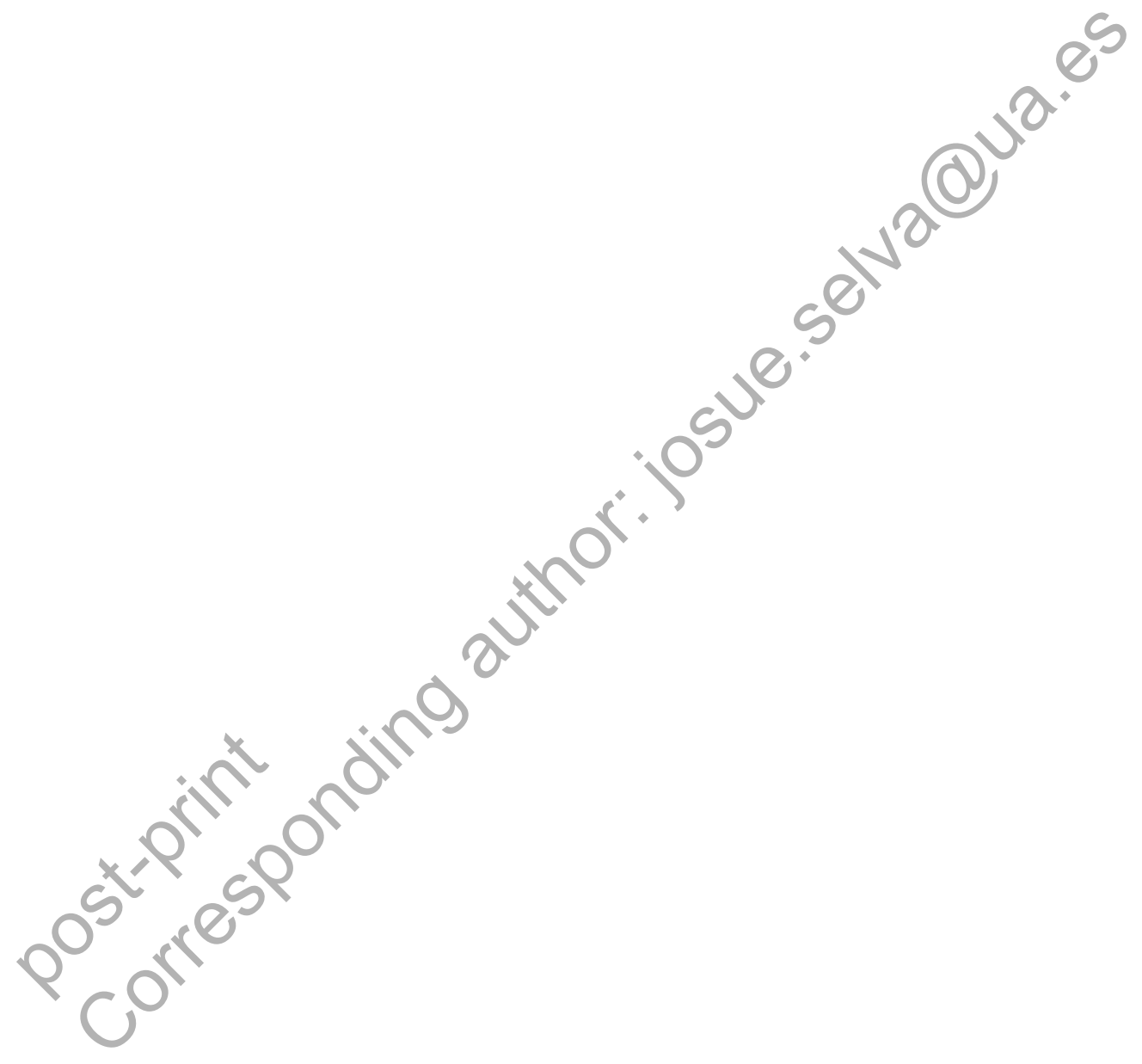

